\title{
Anarchy and Anarchism \\ Towards a Theory of Complex International Systems
}

\begin{abstract}
The use of 'anarchy' in international relations theory appears very different from its incarnations in political philosophy. Whilst realist scholars have used anarchy to describe an absence of centralised political authority in which states wield differential power, political philosophers in the anarchist tradition have mounted a critique of the coercive and compulsory powers of states themselves. This article argues for reconceptualising 'anarchy' in international relations theory using insights from complexity theory.
\end{abstract}

\begin{abstract}
We would describe the international system as a complex adaptive system, which has a tendency to self-organisation. Furthermore, in distinct contrast to Waltz, we argue that the international system has to be seen as embedded within a range of physical systems, and other social systems including those which reproduce a range of (gendered, racial, class-based, colonial) relations of domination. Here insights from anarchist social ecologism can be utilised to further accounts of hierarchy and dominance within international relations.
\end{abstract}

Keywords: complexity theory, anarchy, international systems, intersectionality, social domination

This article brings together insights from complexity and anarchist thinking to develop an alternative conceptualization of international relations. While these two bodies of thought might not at first instance seem to be compatible, we argue that there are considerable areas of overlap. In particular both explore the possibilities for the development of order without a specific source of authority. An anarchist view of society is of one 'which organizes itself without authority.' ${ }^{1}$ Complexity theorists describe this as self-organisation, whilst an equivalent from anarchist theory would be Kropotkin's notion of mutual aid. ${ }^{2}$ Hence both pose similar questions in terms of thinking about social organization. But their differences also suggest possibilities for collaboration. Complexity theorists have been interested in exploring the processes of self-organization, and the ways in which social systems overlap and are embedded in non-human systems. Anarchist thinking has prioritized an analysis of hierarchy and exploitation. While sharing a common focus of analysis, these two areas of thought have much to contribute to each other and to the analysis of international relations.

This article takes as a starting point thinking within International Relations (IR) about anarchy, international systems, and hierarchy. We argue that systems thinking has anticipated elements of a complexity approach, though only in very restricted senses. The second section combines concepts drawn from complexity

1 Colin Ward, cited in Peter Marshall, Demanding the Impossible: A History of Anarchism (London: Harper Collins, 1992), 42.

2 Peter Kropotkin, Mutual Aid: A Factor of Evolution (London: Freedom Press, 1987 [1902]). 
thinking with elements of anarchism, with specific consideration of the work of Kropotkin and Bookchin on the relations between natural and social systems, and in terms of their understanding of multiple forms of social inequality. We argue that both anarchist theory and anarchist politics - opposed as they are, to a range of dominations that they see as interlinked and interdependent - are compatible with complex systems analysis. In a similar way to other critical approaches in international relations, most notably Marxism(s) and feminisms, anarchists understand the world as constituted by social hierarchy and institutionalised oppression and domination. Complex systems approaches enable an understanding of different kinds of systems - those of relations of social domination and those of institutions and related processes, which co-constitute each other. A third section applies these to thinking about international systems.

\section{The Concept of Anarchy in International Relations}

The concept of anarchy has provided a common thread running through much theorising of International Relations. It can be seen for example in Martin Wight's distinction between political theory concerned with the 'good life' and international theory centrally interested in 'survival'. ${ }^{3}$ In Waltz's systemic theory anarchy becomes the defining or 'ordering principle' of international relations. ${ }^{4}$ Waltz's systemic approach is significant because he argued that a holistic approach to the study of international politics was necessary - there were 'forces at play at the international, and not at the national, level. ${ }^{5}$

Waltz argued that all political systems comprised three elements: an ordering principle; the characteristics of the units; and the distribution of capabilities. The ordering principle described the relationship between the units - this could be either hierarchic, or anarchic. The ordering principle is the key element of Waltz's account as it determines all that follows in terms of the theory. Furthermore, a key assumption is that not only is anarchy the 'absence of government', it is also 'associated with the occurrence of violence'. 6 Anarchy both describes the ordering principle of the international system, and it also dictates the key form of state activity. 'Self-help is necessarily the condition of action in an anarchic system'. ${ }^{7}$

Waltz's significant contribution was his attempt to isolate what constitute system level forces; in a sense, to analyse what the term 'international' means. However this focus also opened his work up to a major criticism - without an analysis of the unit level it was difficult to see how we might understand change. ${ }^{8}$ Neorealism was unable to predict the end of the Cold War (a change in the system), nor to provide

\footnotetext{
3 Martin Wight, 'Why is there no International Theory?' in Diplomatic Investigations: Essays in the Theory of International Politics eds. Herbert Butterfield and Martin Wight (London: George Allen and Unwin, 1966), 33.

$4 \quad$ Kenneth N. Waltz Theory of International Politics (New York: Random House, 1979), 88.

5 Ibid., 79.

$6 \quad$ Ibid., 102.

$7 \quad$ Ibid., 111.

$8 \quad$ See, for example, Friedrich Kratochwil, 'The Embarrassment of Changes: Neo-Realism as the Science of Realpolitik without Politics', Review of International Studies 19, No. 1 (1993): 63-80; William C. Wohlforth, 'Realism and the End of the Cold War', International Security, 19, No. 3 (19941995): 92.
} 
an account of how it happened. A change of system, which for Waltz would mean the development of a world government, was not conceivable. For Waltz then, the term anarchy, as a descriptor of the international system, is linked to the popular stereotype of relative chaos and disorder; only stabilised by a particular kind of hierarchy bipolarity.

Such a view of the organisation of international systems has not been without its critics and alternate formulations. Milner observed that there was more than one way of thinking about anarchy. It could be seen as disorder, or as the absence of government. ${ }^{9}$ Both of these characterisations were open to criticism, as was a sharp division between an anarchical international order and a hierarchical domestic order. Order existed in various forms in the international realm, and while there was a lack of government 'with a Weberian cast to it'; this did not mean there was an absence of 'governing institutions and a body of international laws. ${ }^{10}$ English School approaches have been at the forefront of providing a more nuanced account of anarchy. Bull's account of an 'anarchical society' provides a critique of the disordered, or 'Hobbesian' account as he describes it. ${ }^{11}$ Anarchy is a 'fact' for Bull in the sense that 'it is obvious that sovereign states, unlike the individuals within them, are not subject to a common government.' 12 However the lack of common government does not necessarily equate to a lack of order. In 'international society' common interest, rules and institutions maintain a certain degree of order. English School analyses have also contributed to the analysis of different forms of international system and in particular the degree of centralisation of power. ${ }^{13}$ Watson argued that international systems constitute 'a notional spectrum between absolute independence and absolute empire.' ${ }^{14}$ Furthermore systems were always in transition with a tendency to oscillate between the two extremes, with a tendency for the 'gravitational pull of the pendulum' to be away from the extremes and towards the centre - 'a concert or multiple hegemony'. ${ }^{15}$

More recent attention, perhaps related to the perception of the US as a unipolar power, has turned to the view of the international system as hierarchical. David Lake's detailed analysis points to a variety of relations between states with some involved in domination/subordination roles. While Lake does not claim that accepting hierarchy 'does not negate everything we once knew about international politics', it does involve a re-thinking of the ways that states inter-relate. ${ }^{16}$

These analyses develop the notion of anarchy, and prompt a questioning of a sharp distinction between international and domestic politics. There may be anarchy in the sense of no ultimate sovereign power in the international system, but that doesn't mean that there is no order. Likewise anarchy does not, as Waltz suggested,

\footnotetext{
$9 \quad$ Helen Milner, 'The Assumption of Anarchy in International relations', Review of International Studies 17, No. 1 (1991): 69-71.

$10 \quad$ Ibid., 71 and 74.

11 Hedley Bull, The Anarchical Society: A Study of Order in World Politics (Basingstoke: Macmillan, 1977), 25.

$12 \quad$ Ibid., 46

13 Martin Wight, Systems of States (Leicester: Leicester University Press, 1977), Adam Watson, The Evolution of International Society: A Comparative Historical Analysis (London: Routledge, 1992).

$14 \quad$ Watson, Evolution of International Society, 13.

15 Ibid., 324.

16 David Lake, Hierarchy in International Relations (Ithaca NY: Cornell University Press, 2009), 16 and 10-12.
} 
mean that units are undifferentiated. Hierarchy may suggest that sovereign equality is not so equal after all. Waltz's work pointed to the presence of systemic level forces in international politics, but his approach failed to capture the dynamic and coevolutionary character of unit and system interactions, and inter-system interactions. Other views of the international system, in particular those influenced by the English School, have pointed to the possibilities of organization, or the development of an increasingly multifaceted 'society' even where there is no final and absolute power. Likewise, as Lake has indicated, within anarchy there are relations which reflect differing power relations. Such analyses suggest that there is much more to anarchy than Waltz suggested. In developing a complexity and anarchist theory influenced account of international relations we would draw on the importance of system level effects (or, for complexity theorists, emergence), forms of self organization that English School writers have discussed, and on power relations reflecting inequalities between states. Yet while these contributions provide more nuanced accounts of international relations they fail to provide an analysis of the origins of such order or of hierarchy. Furthermore they remain within a state-centred framework. It is here that we argue that insights from complexity thinking and anarchist political theory can be utilised to move the debate forwards. In the next section we introduce some of these concepts, while the third section indicates how these can be applied to thinking about international systems.

\section{Complex systems and anarchism}

'Complexity science' or 'complexity theory' are catch-all terms to describe a variety of approaches emerging from the sciences and more recently applied in the humanities and social sciences to support a range of eclectic positions. ${ }^{17}$ Complexity theory offers us a way to rework the concept of system which overcomes some of the problems encountered by theorists of international relations. Four aspects of complex systems are particularly relevant - self organization; non-linearity; openness; and coevolution. The notion of 'system' has incurred severe criticism within the social sciences, often being held unable to account for the dynamic qualities of social relations and often dramatic processes of change, or unable to account for unpredictable and complicated patterns of change.

In complexity science, natural systems are understood to exist in a web of connections with other systems and are internally complex. The term 'emergent properties' describes specific features that become apparent at a certain level of systemic complexity; but which are not evident at lower levels. This is a nonreductionist position in which phenomena can only be grasped through an examination of their interactions, rather than just considering the sum of their parts. Thus in ecology for example, systems are understood as communities of organisms which link together in a network. ${ }^{18}$ Complexity scientists often speak of systems as

\footnotetext{
17 For a discussion of the varying ways that complexity thinking has been applied in the social sciences see Erika Cudworth and Stephen Hobden, 'More than a Metaphor? Complexity in the Social Sciences', International Journal of Interdisciplinary Social Sciences 4, no. 4 (2009): 59-70.

18 Frijtof Capra, The Web of Life: A New Synthesis of Mind and Matter (New York: Harper Collins, 1996), 34-5
} 
'nested', with larger scale systems enclosing myriad smaller scale systemic processes. ${ }^{19}$ One of the most common and simple elements of the complexity notion of system is the distinction between a system and its environment which is simply that the system has boundaries, is delimited and distinguishes itself from its environment, that is, everything which is outside it. ${ }^{20}$ Although distinct, systems interact with one another in a way which has been referred to as 'coupling'. ${ }^{21}$ Coupled systems may themselves be self reproducing, so they may come to depend on each other for the preservation of their identities.

Systems have 'autopoiesis' and are self-making, self-reproducing, selfdefining or regulating. A system then, has internal processes which internally connect its elements and actively reproduce the system as a whole. A controversial and wellknown model is earth systems science. James Lovelock developed the hypothesis that the earth was a 'superorganism' able to regulate its own temperature. ${ }^{22}$ A vast network of feedback loops bring about such regulation, and link together living and non-living systems. Regulation also takes place through 'symbiogenesis' - the merging of different species in complex arrangements and developments of cooperation and creativity. ${ }^{23}$ In this model, the earth constitutes a single system within which multivariate networks of systems exist, implicating all species, in symbiogenic relations assuming multiple forms. So there are different levels of organized complexity here, and social and natural systems are interlinked.

A further property of a complex system is the tendency to fluctuate between periods of linearity and non-linearity. This has enormous implications for the analysis of cause and effect and for social analysis in general. According to Beaumont in nonlinear systems 'inputs may vary widely and unpredictably from output'. ${ }^{24}$ In linear relations there is a proportionate and non-varying relationship between cause and effect. In the simplest of terms if $a=b$, then $2 a=2 b$. If I throw a ball twice as hard it will go twice as far. In non-linear relations such a direct relationship does not exist, and the connection between cause and effect is much harder to appreciate. The major implication of this is that very minor causes can create very major effects. The classic example of this was the question raised by the meteorologist Edward Lorenz - could a butterfly flapping its wings in Brazil cause a tornado in Texas? ${ }^{25}$ The term used by complexity theorists to describe this phenomena is 'sensitivity to initial conditions': very minor changes in the initial conditions of a system can result in markedly differing end points.

19 C.S. Holling, Lance H. Gunderson, and Garry D. Peterson, 'Sustainability and Panarchies' in Panarchy: Understanding Transformations in Human and Natural Systems eds. Lance H. Gunderson and C.S. Holling (Washington: Island Press, 2002), 68-9.

20 Capra, The Web of Life.

21 Humberto R. Maturana and Francisco J. Varela, Autopoiesis and Cognition: The Realization of the Living (Dordrecht: Kulwer Academic, 1980), 109.

22 James Lovelock, Ages of Gaia: A biography of our Living Earth, $2^{\text {nd }}$ edn. (Oxford: Oxford University Press, 2000), 15.

$23 \quad$ Lynn Margulis, and Dorion Sagan, Microcosmos (New York: Summit, 1986), 119.

24 Roger Beaumont, The Nazis'March to Chaos: The Hitler Era Through the Lenses of ChaosComplexity Theory (Westport CO: Praeger, 2000), 9.

25 Lorenz's original paper, 'Predictability: Does the Flap of a Butterfly's Wings in Brazil Set off a Tornado in Brazil' presented to the $139^{\text {th }}$ Meeting of the American Association for the Advancement of Science is reprinted in Edward Lorenz, The Essence of Chaos (Seattle: University of Washington Press, 1993), 181-4. 
Systems are also 'open' because they utilize a continual flux of matter and energy in order to remain alive, whilst also exhibiting closure in maintaining a (relatively) stable form. ${ }^{26}$ One of the most influential theorists has been Ilya Prigogine who found in apparently chaotic situations far from chemical equilibrium, that coherent, structured, ordered patterns emerged. ${ }^{27}$ Changes are processed by systems through feedback loops which synthesize new information and result in the dynamic qualities of systems. Feedback can result in stability, or if there is positive feedback and a change is reinforced rather than dampened down, dramatic shifts can take place and a system can be said to have become 'path dependent'. However, the instability of these dynamic systems means that even a path dependent system cannot be understood to be developing along a linear trajectory. Rather, systems can bi-furcate, and shift to new paths, they may dissipate or re-order themselves and perhaps move on to a higher level of complexity. Systems are characterized in this view by constant change, some of it abrupt, all of it unpredictable. ${ }^{28}$

Systems change though interaction and complexity scientists have used a notion of co-evolution to describe how systems complexly adapt to their environment. Rather than simply impacting on one another (as implied by a hierarchical model of system) systems have complex reactions to relations with other systems (due to the presence of their own internal systemic features). All individual interacting systems, often of different levels of complexity and scale are changed in their interaction. Stuart Kaufman uses the concept of 'fitness landscape' in understanding the complex co-evolution of species, arguing that the environment or 'landscape' each system faces is altered as a result of changes in all the various other systems that collectively constitute the landscape. ${ }^{29}$

These concepts may be usefully developed in the study of social and political life. They allow for differentiated systems, with various layers and levels of emergent properties and powers, and do not presume that relationships between levels are fixed or hierarchical in character. In addition, there is the presumption that systems interrelate, overlap each other, may exist within each other and are co-constitutive. There is no presumption of stasis, but rather, the notion that systems are constantly making and remaking themselves, and may, given their inevitable interactions with other systems, change and shift radically.

There have been some attempts to apply ideas from complexity approaches to the study of International Relations, and Kavalski has argued that the approach will inspire a fifth debate. ${ }^{30}$ Rosenau, for example drew on complexity inspired concepts

\footnotetext{
$26 \quad$ Ilya Prigogine, 'The Philosophy of Instability', Futures 21 no. 4 (1989): 396-400.

27 Ilya Prigogine, and Isabelle Stengers, Order Out of Chaos: Man's New Dialogue with Nature. (New York: Bantam, 1984), 146.

28 C.S. Holling, Lance H. Gunderson, and Donald Ludwig, 'In Quest of a Theory of Adaptive Change' in Panarchy: Understanding Transformations in Human and Natural Systems eds. Lance H. Gunderson and C.S. Holling (Washington: Island Press, 2002), 14.

$29 \quad$ Stuart Kauffman, The Origins of Order: Self-organization and Selection in Evolution (Oxford: Oxford University Press, 1993); Stuart Kauffman, At Home in the Universe: The Search for Laws of Self-organization and Complexity (London: Viking, 1995).

$30 \quad$ Emilian Kavalski, 'The Fifth Debate and the Emergence of Complex International Relations Theory: Notes on The Application of Complexity Theory to the Study of International Life', Cambridge Review of International Affairs 20, no. 3 (2007): 435 - 454.
} 
in his study of turbulence. ${ }^{31}$ Likewise Jervis drew on complexity notions in his systems based analysis, and Cederman used the concept of emergence to provide the basis for an account of the development of states and nations. ${ }^{32}$ It has also been suggested by Gaddis that complexity approaches have much to contribute to the writing of history. ${ }^{33}$ Further strong support for the use of complexity influenced approaches has been made by Harrison who brought together a number of writers working on network analysis. ${ }^{34}$

It is, however, important to point out that the approaches to complexity which have emerged thus far within IR reflect the diverse ways that complexity has been appropriated in the social sciences more generally, as previously discussed. A significant distinction would be between those that seek to develop a network analysis approach, ${ }^{35}$ while others have focussed on the analysis of the intersectionality of complex adaptive systems. ${ }^{36}$ As discussed below, we favour approaches that build on analyses of complex adaptive systems. In International Relations terms these allow for the analysis of the co-evolution between units and systems and the inter-relations between systems, and crucially enable the analysis of the international system as embedded in a range of other human and non-human systems. ${ }^{37}$

Although an early enthusiast for the application of complexity in the study of international relations, Rosenau has become more circumspect, suggesting that there are problems with the analysis of authority. In particular, 'social systems have structures of authority that may be inconsistent with the definition of complex adaptive systems... authority serves to minimize complexity.' 38 While power, authority and hierarchy have been under-theorised in complexity approaches, ${ }^{39}$ attempts have been made to include an analysis of power. ${ }^{40}$ A further fruitful avenue is to explore the analyses of hierarchy developed in anarchist political theory.

\section{Order vs hierarchy: Mutual Aid and social domination}

\footnotetext{
31 James Rosenau, Turbulence in World Politics: A Theory of Change and Continuity, (London: Harvester Wheatsheaf, 1990).

32 Robert Jervis, System Effects: Complexity in Political and Social Life (Princeton NJ: Princeton University Press, 1997); Lars-Erik Cederman, Emergent Actors in World Politics: How States and Nations Develop and Dissolve (Princeton NJ: Princeton University Press, 1997).

33 John L. Gaddis, The Landscape of History: How Historians Map the Past (Oxford: Oxford University Press, 2002).

$34 \quad$ Neil E. Harrison, ed. Complexity in World Politics: Concepts and Methods of a New Paradigm (Albany NY: State University of New York Press, 2006).

35 For example, Ravi Bhavnani, 'Agent-Based Models in the Study of Ethnic Norms', in Complexity in World Politics: Concepts and Methods of a New Paradigm, ed. Neil Harrison (Albany NY: State University of New York Press, 2006).

36 Especially Sylvia Walby, Globalization and Inequalities: Complexity and Contested Modernities (London: Sage, 2009).

37 Such an analysis is developed in Erika Cudworth and Stephen Hobden, Posthuman International Relations: The Politics of Complex Ecologism (London: Zed, forthcoming).

38 David Earnest and James Rosenau, 'Signifying Nothing? What Complex Systems Can and Cannot Tell us about Global Politics', in Complexity in World Politics: Concepts and Methods of a New Paradigm, ed. Neil Harrison (Albany NY: State University of New York Press, 2006), 144.

39 See, for example John Urry, Global Complexity (Oxford: Polity, 2002).

$40 \quad$ See Walby, Globalization and Inequalities.
} 
As we have seen, a key insight of complexity approaches is the notion of selforganisation - that order can arise without a specific orderer. Here there is a considerable overlap with key anarchist contributions to the study of politics. Anarchist political theory has also focussed on the analysis of hierarchy. In the work of Murray Bookchin in particular, the analysis of various kinds of social hierarchies and forms of institutionalised social domination is key, and Bookchin's understanding of these as co-constitutive is highly compatible with a complexity understanding of social systems. Both Bookchin and Kropotkin are interested in contemporary scientific debates, at least in part because they consider the relationship between natural systems and social forms, and develop understandings of the world that are compatible with complexity approaches. In Bookchin's case, complexity is specifically referenced and critiqued, and, interestingly, it is Kropotkin who might be read as more clearly a proto-complexity theorist. When the insights from these approaches to anarchism are seen through a complexity lens, they offer the possibility of viewing international politics and the organisation of the international system from a different perspective.

In addition to his work as a political theorist and revolutionary, Kropotkin was a geographer and a biologist. His experiences in Eastern Siberia and Northern Manchuria led him to challenge the ways in which Darwin's theory of evolution had been interpreted. Kropotkin argued that the metaphor of the survival of the fittest had become the central way in which evolutionary theory had been explained. The focus on the competitive aspect of evolutionary theory over-stated one aspect of evolution, ignoring in particular, the significance of co-operation within species. Kropotkin claimed that "sociability is as much a law of nature as mutual struggle. ${ }^{41}$ Starting with an examination of non-human animals Kropotkin claimed that 'natural selection continually seeks out the ways precisely for avoiding competition as much as possible. ${ }^{42}$ He noted how few animal species exist by directly competing with each other compared to the numbers who do practice mutual aid, and that those who do are likely to experience the best evolutionary prospects. Given this history it is therefore unlikely that humans, 'a creature so defenceless ... at his beginnings' should have flourished so successfully without co-operation. ${ }^{43}$ Sociability is inherent in the success of humans as a species. ${ }^{44}$ Drawing upon the work of anthropologists, and the observations of Darwin himself, ${ }^{45}$ Kropotkin argued that from the earliest times human beings were social rather than individualistic. Studying the development of medieval cities, Kropotkin remarked on the notable similarities between them, despite the different circumstances from which they occurred, each the "varying result of struggle between various forces which adjusted and re-adjusted themselves in conformity with their relative energies, the chances of their conflicts, and the support they found in their surroundings. ${ }^{46}$ Complexity theorists would see this as an example of co-evolution - systems developing as a result of interactions with their environment. Moving on to his own time period, despite attempts by the state to eradicate all forms of mutual aid, Kropotkin found many examples of sociability. The

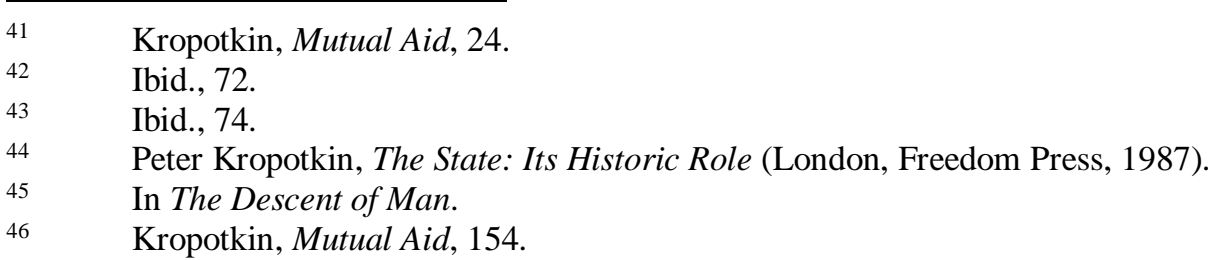


appearance of labour unions is one key example, including the frequent examples of co-operation between unions during times of hardship. Mutual aid has been, Kropotkin argues, a feature of human existence that has widened its reach, ultimately potentially to the whole human species, whilst at the same time being refined. ${ }^{47}$

There is much in Kropotkin's analysis that could be equated to the central complexity concepts that we have previously described. The notion of mutual aid appears to be an organising force across a range of species, as a 'factor of evolution' it is not specifically a human attribute, but one which has enabled a range of species to flourish. This would equate closely to the notion of self-organisation in complexity theory. Self-organisation points to the tendency of units to interact with each other to produce ever more complex systems. These interactions produce emergent features, which can be seen in Kropotkin's works as the appearance of ever more complex forms of social organisation, involving co-operation between the individuals concerned. Mutual Aid stressed the process of evolution as one where successful adaptation and exploitation of evolutionary niches is secured by species' propensity for co-operation and solidarity. ${ }^{48}$ This is very similar to 'symbiogenesis', a notion used extensively in complexity biology. ${ }^{49}$

Hence both 'mutual aid' and complexity theory see the possibility of order without a sovereign body, and instances of this order have been observed across a range of social and non-social sciences. ${ }^{50}$ This order can be spontaneous and progressive. As Marshall notes, anarchists 'consider society to be a self-regulating order which develops best when least interfered with. ${ }^{51}$ The core of Kropotkin's work was a critique of the state of nature as perceived by Hobbes, and he noted that 'the Hobbesian philosophy has plenty of admirers still. ${ }^{52}$ Life in various forms was not a war of all against all, and while conflict was apparent across the animal world, there was also a story to be told from a perspective of co-operation.

In addition, Kropotkin's political theory follows trajectories of changes in social relations, institutions and processes through a historically evolutionary model in which societies move through stages and points, acquiring increased complexity and diversity. ${ }^{53}$ His intention was not only to show the interrelation between social and ecological changes, and the continued significance of 'mutual aid' but also to set out the co-evolved properties of systemic relations of social domination. For example, Kropotkin provides an historical account of the emergence of the modern political system from the medieval period in Europe wherein there is a coalescing of military

\footnotetext{
$47 \quad$ Ibid., 234.

48 R. van Duyn, Message of a Wise Kabouter (London: Duckworth, 1969), 21.

49 Lynn Margulis and Dorion Sagan, Acquiring Genomes: A Theory of the Origins of Species (New York: Basic Books, 2002), 205; also Stuart Kauffman, At Home in the Universe: The Search for Laws of Self-Organization and Complexity (Oxford: Oxford University Press, 1993). For a critique of Margulis and a rather different version of co-evolution see Scott F. Gilbert, "The Genome in its Ecological Context: Philosophical Perspectives on Interspecies Epigenesis, Annals of the New York Academy of Science 981 (2002): 202-18.

$50 \quad$ For an introduction to some of this literature see Erika Cudworth and Stephen Hobden, 'The Foundations of Complexity, the Complexity of Foundations', Philosophy of the Social Sciences, forthcoming.

$51 \quad$ Marshall, Demanding the Impossible, 13.

52 Kropotkin, Mutual Aid, 75.

53 Miller, Anarchism, 182.
} 
elites with new forms of judicial authority, and a breaking down of 'primitive village communities'. This political system is also a product of the dynamics of feudal class relations and is a class-based structure that is seized by the emerging bourgeoisie with the development of capitalism. ${ }^{54}$ Kropotkin did not consider class to be the only factor in establishment of social domination; also important is the 'Triple Alliance' of the state with the institutions and practices of military power with judicial and (Christian) religious authority. ${ }^{55}$ The development of capitalism as a system is co-constituted with the development of modern political institutions and relations. Thus the coevolution of social/natural systems in Kropotkin's account is not without politics. Rather, Kropotkin also maps a range of sets of oppressive relations and institutional systems. These insights are compatible with a complexity understanding of social relations as both multiple and systemic.

Many of Kropotkin's ideas are elaborated in the work of Murray Bookchin, who has been instrumental in linking anarchism to green social and political thought in his advocacy of 'social ecology'. In his best known work, Bookchin gave an account of the emergence of social hierarchies. These emerged with, first, the oppression of women, proceeding to the exploitation and oppression of other groups of humans, socially stratified according to age, 'race', class and sexuality. ${ }^{56}$ The notion of overlapping and intersected forms of social domination which are systemic and co-constituting is clearly compatible with a complex systems analysis of social domination. In addition, Bookchin's understanding of the hybridized and amorphous nature of contemporary political systems embedded firmly in the social fabric and constantly in the processes of arranging and rearranging social life - maintaining themselves - can be given a complexity reading. ${ }^{57}$

Humans as a species have developed to an exceptional degree such that they have produced a 'second nature' a uniquely human culture, a wide variety of institutionalized human communities, an effective human technics, a richly symbolic language, and a carefully managed source of nutriment. ${ }^{58}$ This is a development out of 'first nature', or 'nonhuman nature'. An important distinction that has emerged between human and non-human nature is hierarchy, 'institutionalized and highly ideological systems of command and obedience', which are an 'exclusive characteristic of second nature. ${ }^{59}$ Hierarchy is not a defining feature of second nature, but one that has emerged historically. Earlier, organic societies were non-hierarchic, and characterised by usufruct and complementarity, or mutualism, where care was taken for all members of society, without attributing particular status to differences between its members. ${ }^{60}$ Over time hierarchic relations emerged related primarily to gender, age and lineage, developing into the range of hierarchic distinctions that typify the contemporary world. Our current malaise is a result of an evolutionary history containing two competing logics - that of spontaneous mutualistic ecological

\footnotetext{
$54 \quad$ Kropotkin, The State, 17-21.

$55 \quad$ Ibid., 33.

$56 \quad$ Murray Bookchin, The Ecology of Freedom: The Emergence and Dissolution of Hierarchy (Edinburgh: AK Press, 2005 [1991, 1982])

$57 \quad$ Ibid., Ecology of Freedom, 191-200.

58 Murray Bookchin, The Philosophy of Social Ecology: Essays on Dialectical Naturalism (Montreal: Black Rose Books, 1990), 162.

$59 \quad$ Bookchin, Ecology of Freedom, 24.

60 Ibid., 26.
} 
differentiation, and that of social domination. ${ }^{61}$

In some ways, complexity theory is a latent presence in Bookchin's work. Similarly to Kropotkin, he considers that nature is unified despite its diversity, and species exist in relations of mutual interdependence and co-operation. ${ }^{62}$ The concept of co evolution runs through both Mutual Aid and The Ecology of Freedom, and Kropotkin's representation of 'life' in terms of multi-leveled and nesting systems, or 'federations' of life forms, informed both Bookchin and a range of contemporary social theorists. ${ }^{63}$ The Ecology of Freedom outlined an evolutionary model of human social development. Bookchin suggested that social hierarchy emerged in the early Neolithic period with the establishment of rudimentary forms of government and the development of warrior groups to protect and extend territory. In his descriptions of evolutionary patterns and pathways, Bookchin considered that:

The universe bears witness to an ever-striving developing - not merely 'moving' substance, whose most dynamic and creative attribute is its ceaseless capacity for self-organization into increasingly complex forms. ${ }^{64}$

Drawing on Lynn Margulis, Bookchin argued that there are symbiotic relations in 'nature' between systems of land, sea and atmosphere, and forms of evolutionary cooperation/co adaptation. ${ }^{65}$ We participate in the evolutionary process, co-evolving with our environments and other species. However, whilst complexity science is not teleological, Bookchin's use of it is very much shaped by his Enlightenment narrative which tells of an evolution to a higher level of complexity and consciousness culminating not just in ever increasing diversity, but in a state of 'free nature' in which intra human hierarchies are dissolved and the domination of the environment is no more. Bookchin certainly seems to be influenced by complexity thinking in terms of the language and concepts he used, but was critical of systems thinking in general. In a critique of Capra, he stated that 'theories of indeterminacy and probability in physics are rendered coequal with human autonomy and social freedom without the least regard for the fact that the human domain is marked by a staggering complexity of social institutions, wayward individual proclivities, diverse cultural traditions, and conflicting personal wills. ${ }^{66}$ In short, the social world is different.

Bookchin was also concerned that complexity theory does not entail a particular political project when he observes with reference to Prigoginian systems theory that 'a system of positive feedback allows for no concept of potentiality. ${ }^{67}$ In many ways, this concern is well founded, as the ambiguities and different trajectories in scientific complexity theory have meant that it has been appropriated by kinds of social and political theorizing (such as postmodernism) to which Bookchin is so

61 Andrew Light, 'Bookchin and/as social ecology', in Social Ecology After Bookchin ed. Andrew Light (New York/London, The Guilford Press, 1998), 7.

$62 \quad$ Bookchin, The Modern Crisis, 26.

63 See for example, Donna Haraway, When Species Meet (Minneapolis/London: University of Minnesota Press) 42

$64 \quad$ Bookchin, Ecology of Freedom, 458.

65 Lynn Margulis's Symbiosis in Cell Evolution (San Francisco: W.H. Freeman and Co., 1981) was then current.

66 Bookchin, Philosophy of Social Ecology, 151

67 Ibid., 192 n. 15. 
implacably hostile. ${ }^{68}$ Yet some complexity positions have been usefully deployed by those analysing the politics of domination and arguing for change. ${ }^{69}$ Various contemporary political ecologisms see human communities in a complex network of relations with non-human nature - relations characterised by reciprocity and interdependency, and also importantly, by exploitation and domination. Complexity theory can help us to consider intermeshing multiple systems as both analytically distinct, whilst being also, mutually constitutive. The domination of non-human nature is a system of exploitative relations, that overlaps and interlinks with other systems of power and domination based on gender, capital, ethnic hierarchy and so on.

We would concur with Bookchin that the social world is different, but because we would argue that because human systems are embedded in non-human systems that his separation between 'first' and 'second' natures as problematic. What is needed is a conception of different systems of social domination that are complex and intersected, with the possibility of capturing the scales and levels of different kinds of systems. ${ }^{70}$ Here, the notion of 'panarchy' may be useful. ${ }^{71}$ This draws in ecosystems, political, economic and social systems, alongside a notion of local, specific human cultural systems. Panarchies are living systems, conceived of as internally dynamic and historically non-static structures which develop mutually reinforcing relationships which are co-constitutive and adaptive. It is not only panarchies involving human systems which demonstrate decision making properties, rather a huge variety of nonhuman animals make collective decisions and engage in individual decision making behaviour with a cumulative systemic effect. ${ }^{72}$ These self-organised interactions do not result in stability. Rather, systems may be vulnerable - ecosystems may be undermined by human endeavours, political systems may be vulnerable due to the collapse of natural systems on which populations depend for resources. Also, systems in interaction are themselves complex systems with their own emergent properties. ${ }^{73}$ This allows for qualitative and quantitative differences between 'natural' and 'social' systems, in particular, because the self-organizing properties of intra human systems outstrip those of natural systems. ${ }^{74}$ Whilst social and natural systems may be structured by similar processes, social systems have properties of consciousness and reflexivity. They also reproduce and develop formations of social power, which, like capitalism, patriarchy and so on, are usefully understood as complex adaptive

68 For an account of the use of 'chaos' orientated approaches in complexity science and its use in the development of postmodern theory see Katharine N. Hayles, ed., Chaos and Order: Complex Dynamics in Literature and Science (Chicago, Chicago University Press, 1991).

69 See for example Sylvia Walby, 'Complexity theory, systems theory and multiple intersecting social inequalities.' Philosophy of the Social Sciences, 2007, 37 (4), 449-470.

70 We have described this as 'differentiated complexity'. See Cudworth and Hobden, 'More than a metaphor', 67-68.

71 C. S. Holling, et al., 'Sustainability and panarchies'.

72 Ibid., $72-87$.

73 C. S. Holling, Stephen R. Carpenter, William A. Brock and Lance H. Gunderson, 'Discoveries for sustainable futures', in Panarchy: understanding transformations in human and natural systems eds. Lance H. Gunderson and C.S. Holling (Washington, Island Press, 2002), 411.

$74 \quad$ Frances Westley, Stephen R. Carpenter, William A. Brock, C.S. Holling, and Lance H. Gunderson et al. 'Why systems of people and nature are not just social and ecological systems' in Panarchy: understanding transformations in human and natural systems eds. Lance $\mathrm{H}$. Gunderson and C.S. Holling, eds.. (Washington, Island Press, 2002), 104-5. 
systems.

In the writings of Kropotkin and Bookchin, there is considerable overlap with complexity theorists. Complexity theorists have looked at how order emerges across a range of physical and animal situations whereas anarchist political theorists have focused their attention on the human world. Where anarchist work is particularly significant is the analysis, and critique of forms of hierarchy in human societies. In the next section we reflect on how these ideas can be combined with reference to thinking about international relations.

\section{International politics as complex systems}

As we have seen in the previous section there are considerable overlaps and complementarities between complex and anarchist thinking. Combining insights from these two approaches offers different ways of thinking about connections and linkages in international politics. It offers a framework with which to examine interlinked and multileveled relations, between different scales of activity and processes and the ways in which systems reproduce and change. This section examines the contribution that concepts derived from complexity and anarchist approaches can be applied to thinking about international systems. A number of features of complex systems are relevant to the study of international systems; in particular we examine the interconnected notions of self-organisation, open systems, non-linearity, and bifurcation.

Complexity understandings of systems undermine the realist conception of states as solid 'billiard balls', relatively unchanged by the process of interacting with each other and with the international system. For complexity theorists, systems are self-organising to the extent that the features of a system can be modelled without reference to factors outside the system. This does not mean that a system is closed and that it has no relationship with other systems - for complexity theorists, particularly within the social sciences, a key feature of systems analysis is such interaction. However complexity theorists suggest that a particular system can be analysed by considering the interaction of its parts independently from other systems. An international system would appear to be a paradigmatic example of a self-organising system, in that under anarchy there is no overall direction to the system. The patterns and regularities that there are, including the appearance of hierarchies, materialize from the actions of the units.

Emergence has been described as 'the process by which patterns or globallevel structures arise from local-level processes'. ${ }^{75}$ In other words theses are features that can only be explained by an examination of a system as a whole. There are features which cannot be evaluated purely from an examination of the interactions of the parts. When units inter-act in a complex system properties can be seen to be present which are not manifest at the unit level. This is, of course, a feature of much systems analysis, and formed the centre point of Waltz's approach to the study of systems. However, complexity theorists are much more ready to collapse the levels of analysis, and see the inter-connections between different levels (or nested systems) as central to analysis. Rather than depicting the international systems as a closed system

75 Kevin Mihata, "The Persistence of "Emergence" in Chaos, Complexity, and Sociology: Myths, Models, and Theories eds. Raymond A. Eve, Sara Horsfall, and Mary E. Lee (London: Sage, 1997), 31. 
which, at least in analytical terms, can be sealed off from other levels, systems are viewed as 'open' with effects potentially having ramifications through systems.

What might be the emergent properties for an international system? We would argue that three types of emergent properties might be apparent. First, those associated with institutional structures. All international systems have developed sets of norms, rules, and even supra-governmental organisations to oversee their interactions. Most accounts of international organisation would point to a rapid acceleration in the levels of institutions in the international system since the start of the nineteenth century - from the loose knit Concert of Europe to a world presided over by international law, and international organisations such as the United Nations and the World Trade Organisation. ${ }^{76}$ For many complexity thinkers the deepening web of institutional arrangements would be unsurprising. These institutional properties would be close to the analysis of international systems provided by Wendt, and his view of changing international cultures would mirror this pattern of increasing complexity. ${ }^{77}$ However, most complexity thinkers would reject his view that a world state is inevitable. ${ }^{78}$

Emergent properties can also be seen in relational terms. Waltz's discussion of polarity and the different character of international systems would apply here. We would seek, however, to expand the range of relations analysed to also incorporate economic, ideological, patriarchal, and political forms of domination, exploitation and exclusion. Wallerstein's account of a capitalist world economy would provide a starting point for an analysis of systemic economic relations. The capacity to generate, propagate and impose ideological positions on the organisation of society would also be included under this heading. Baker has brought complexity theory together with a Wallerstinian analysis to illustrate processes of centralization and peripheralization. ${ }^{79}$ A long term pattern or 'attractor' in human relations has been centralization and peripheralization. This process sucks energy and resources into the centre, while leading to entropy and chaos in the periphery. 'Centering', Baker argues 'involves both access to and use of resources and the know-how and ideological justification for this', while 'peripheralization involves a loss of control, a diminution or denial of access, of resources and know-how and an ideological schema justifying subservience to and devaluation by the center. ${ }^{80}$ Hence, from a complexity perspective the capacity to generate, propagate and impose ideological positions on the organisation of society would also be included under this heading.

While Baker's analysis might suggest that there are regular patterns to centering and peripheralization, he also stresses that these energy flows are very unstable and that change can be sudden and unpredictable. This highlights a further

\footnotetext{
76 The classic account of this process is Inis Claud, Swords Into Plowshares: The Problems and Progress of International Organization (New York: Random House, 1956). For a more recent discussion, influenced by complexity theory, see Joseph Camilleri and Jim Falk, Worlds in Transition: Evolving Governance Across a Stressed Planet (Cheltenham, UK: Edward Elgar, 2009).

77 Alexander Wendt, Social Theory of International Politics (Cambridge: Cambridge University Press, 1999).

78 Alexander Wendt, 'Why a World State is Inevitable', European Journal of International Relations, 9 no. 4(2003): 491-542.

79 Patrick L. Baker, 'Chaos, Order and Sociological Theory', Sociological Inquiry, 63, no. 2 (1993): 123-149. Also see Patrick L Baker, Centring the Periphery: Chaos, Order and the Ethnohistory of Dominica (Jamaica: The Press - University of the West Indies, 1994).

80

Baker, 'Chaos, Order and Sociological Theory', 136.
} 
property of complex systems; the tendency to fluctuate between periods of linearity and non-linearity. This has enormous implications for the analysis of cause and effect and for social analysis in general. According to Beaumont in non-linear systems 'inputs may vary widely and unpredictably from output'. ${ }^{81}$ Waltz's Theory of International Politics provides a clear example of a linear account of international relations - a bipolar world will be very stable, a multi-polar one less so. In other words, there is a direct relationship between the number of great powers and international outcomes, between cause and effect. However, international history is replete with instances of comparatively minor events leading to major outcomes. A classic example might be the assassination of Archduke Ferdinand in Sarajevo that leads to a series of convulsions that engulfed the world for over 40 years. Pascal's view that the history of the world would have been significantly different had Cleopatra's nose been shorter makes a similar point.

Closely related to the notion of non-linearity is the concept of bifurcation. Capra describes bifurcations as 'critical points of instability'. ${ }^{82}$ They are critical in the sense that they can mark crucial turning points in the trajectory of a system. As such they have the potential to lead to a major change in the characteristics of the system. As Byrne argues, 'systems which have a chaotic dynamic develop through a pattern of bifurcations'. ${ }^{83}$ Another key characteristic of bifurcation points is that 'very small differences in control parameter values determine which path the system will follow' - in other words non-linearity becomes more significant, small changes can have a greater impact. ${ }^{84}$ Furthermore bifurcation points indicate that a system can develop in more than one direction, and it is very hard to predict what path will be taken.

In terms of international systems a bifurcation point could result (in Waltzian terms) in a change in the system, or a change of the system. The end of the Cold War was a bifurcation point, with the collapse of the Soviet Union resulting in a change in the system, from polarity to bi-polarity. Wallerstein argues that we are now in a nonlinear period of international relations which will lead to a bifurcation point which will result in a change of the system - from the Modern World-System to some kind of alternative. ${ }^{85}$

Complexity theorists are also concerned to analyse feedback mechanisms. Jervis describes feedback as: 'A change in an element or relationship often alters others, which in turn affect the original one' ${ }^{86}$ Traditionally international relations theorists have focussed on 'negative feedback'. These are the actions which bring a system back into equilibrium. A central heating thermostat is the classic, non social science, example of a negative feedback system. As a room cools a switch is operated in the thermostat to switch a central heating boiler on which heats the room up again. Such systems are usually described as homeostatic: they always return to an equilibrium position. For realist theorists such as Morgenthau and Waltz the international system is homeostatic as they expect a balance of power (an equilibrium

\footnotetext{
81 Beaumont, The Nazis' March to Chaos, 9.

82 Fritjof Capra, (2007) 'Complexity and Life', in Reframing Complexity: Perspectives from North and South eds. Fritjof Capra, Alicia Juarrero, and Pedro Sotolongo (Mansfield MA: ISCE Publishing, 2007): 14.

83 David Byrne, Complexity Theory and the Social Sciences (London: Routledge, 1998), 170.

$84 \quad$ Ibid.

85 Immanuel Wallerstein, The Uncertainties of Knowledge (Philadelphia PA:Temple University Press, 2004), 104.

$86 \quad$ Jervis, System Effects, 125.
} 
position) to always emerge. If the balance of power is disrupted then negative feedback (such as war, or changes in alliances) will occur to return the system to a balanced position. ${ }^{87}$

Complexity theorists retain an interest in negative feedback, but also point to the significance of positive feedback - those effects which take a system further away from an equilibrium point. In the example of a central heating system, the equivalent would be the thermostat setting off a cooling system, which would make the room even cooler, rather than a heating system which would warm the room up. In international relations positive feedback has become associated with the term 'blowback', and an archetypal example would be the US funding of the Mujahedin to fight the Soviet-backed government in Afghanistan in the 1980s. Some claim this led to the establishment of the Taliban government in Afghanistan which was highly implicated in the plot to attack the US on September $11^{\text {th }} 2001 .^{88}$ The notion of positive feedback has also become linked to the patterns of climate change. There are concerns amongst scientists that as the earth warms stores of carbon dioxide and other greenhouse gases will be released into the atmosphere from frozen peat bogs or the oceans, which will lead to even higher levels of greenhouse gases and even more rapid climate change. Positive feedback takes a system further away from its equilibrium point, and the further a system is from equilibrium the more likely it is to display non-linear behaviour. ${ }^{89}$

The implications of non-linearity, sensitivity to initial conditions and bifurcation are highly significant for the study of international relations. As Elliott and Kiel argue 'Nonlinear dynamics and the related sciences of complexity lead us to question the extent to which we may be capable of both prediction and control in social and policy systems'. ${ }^{90}$ Put simply, while perhaps theoretically possible, the features of complex systems suggest that it is very difficult to make predictions about what future trajectories the international system will take. During linear phases of stability (such as the Cold War) prediction may be possible, but during non-linear phases it is most likely that unexpected outcomes will occur, with large changes to or within systems, and unpredictable relationships between causes and events (for example, small events having major impacts, and major events perhaps little impact). In other words the kind of activities and expectations that can be had for the study of international relations may have to change. As Capra notes:

'we can still make very accurate prediction, but they concern the qualitative features of the system's behavior rather than the precise values of its variables at a particular time. Nonlinear dynamics thus represents a shift from quantity

87 Waltz, Theory, 116-123; Hans J. Morgenthau, Politics Among Nations: The Struggle for Power and Peace, $5^{\text {th }}$ edn. (New York: Alfred A. Knopf, 1973), 186.

88 According to Chalmers Johnson, the term blowback, in this sense, was first used by the CIA to indicated 'unintended and unexpected negative consequences of covert special operations operations'. In Johnson's view 'the attacks of September 11 are blowback in a direct line of descent from 1979'. See Chalmers Johnson, Blowback: The Costs and Consequences of American Empire (London: Time Warner, 2002), xi-xii.

$89 \quad$ Martin Heimann \& Markus Reichstein, 'Terrestrial ecosystem carbon dynamics and climate feedbacks', Nature 451 (17 January 2008): 289-292.

$90 \quad$ Euel Elliott, and L. Douglas Kiel, 'Nonlinear Dynamics, Complexity and Public Policy: Use, Misuse, and Applicability', in Chaos, Complexity and Sociology: Myths, Models, and Theories eds. Raymond A. Eve, Sara Horsfall, and Mary E. Lee (London: Sage, 1997), 68. 
to quality. Whereas conventional mathematics deals with quantities and formulas, complexity theory deals with quality and pattern'. ${ }^{91}$

We can say what a system looks like rather than necessarily where it is going. This might be considered a considerable weakness of complexity approaches. However we would argue that it might be more appropriate to accept that, with complex social systems, we have to expect the unexpected, than to adopt theoretical positions, which while claiming to have predictive capabilities, are extremely unlikely to be accurate (due to the problems of assessing all the factors in social systems, and the difficulty of modelling non-linear relations).

\section{Conclusion}

We have argued that there is the potential for a fruitful dialogue between complexity approaches and anarchist political thought, and have indicated how this can be used to re-think systems approaches in international relations. Both complexity and anarchism have been concerned with issues of order. Through concepts such as emergence and co-evolution complexity provides an analysis of the spontaneous appearance of order, whilst anarchist political thought has provided significant accounts of manifestations of hierarchy. These can be combined, we argue, to enable a number of important theoretical moves to be advanced in the understanding of international politics and analysis of multiple social dominations. Whilst anarchy has been the defining feature of Realist and Neorealist accounts of international relations, political anarchism and the insights of complexity theory provide us with a very different understanding of politics and organisation - the possibility of the emergence of order, without an orderer. This is an order where there have been hierarchies, and particularly dominant actors have attempted to impose particular world views and forms of relations on others. Anarchist political thinkers have consistently illustrated such processes with reference to domestic society. This undermines the Hobbesian pre-occupation of much International Relations theory influenced by a view that nature comprises a struggle for the survival of the fittest and that 'clubs are trumps' in the international political system.

In the work of anarchist social ecologists such as Kropotkin and Bookchin, the notion of emergent order and the embedding of social and political systems within 'natural' systems are fore grounded. What is perhaps most significant in terms of their placing in the anarchist tradition however, is their analysis of social and political systems. Patterns of hierarchy and domination usurp, distort and reconfigure human relations, but also, particularly for Bookchin, structure our co-existence with nonhuman natures. Complexity theory, with its notions of co-existing, interrelated, multilevelled and co-constituted systems enables the capture of the ontological depth of relational systems of social domination (of class, race, ethnicity, gender and so on) and their interaction or intersection. It usually also assumes the co-constitution and co-evolution of social with natural systems. Complexity reinvents our understanding of systems, such as that we might speak of panarchies, configurations both social and natural, which are dynamic, non-linear and unpredictable.

$91 \quad$ Capra, 'Complexity and Life', 13. 
Ultimately, this involves a reconceptualisation of international relations on ontological and epistemological grounds. Ontologically, international relations concerns more than states. States co-exists and co-evolve with a range of actors and these are embedded in a range of other human (economic, ethnic and gendered systems), and non-human systems, rather than as distinct realms. Epistemologically, because complex approaches imply that there are non-linear connections between events and that while there may be periods of regularity, these are likely to end unpredictability, with considerable upheavals in systems. We have suggested here, that this enables both a better understanding of the complicated formations and processes of international politics, and that anarchist theorisation and anarchist politics complements with complex systems analysis. 